\title{
SYNTHESIS AND CHARACTERIZATION OF CARBON MATERIAL OBTAINED FROM COCONUT COIR DUST BY HYDROTHERMAL AND PYROLYTIC PROCESSES
}

\author{
Cipta Panghegar Supriadi ${ }^{1 *}$, Evvy Kartini ${ }^{2}$, Wagiyo Honggowiranto ${ }^{2}$, Kris Tri \\ Basuki $^{1}$ \\ ${ }^{1}$ Nuclear Chemical Engineering, Sekolah Tinggi Teknologi Nuklir (STTN), National Nuclear Energy \\ Agency (BATAN), Yogyakarta 55281, Indonesia \\ ${ }^{2}$ Center for Science and Technology for Advanced Materials, National Nuclear Energy Agency, South \\ Tangerang 15314, Indonesia
}

(Received: January 2017 / Revised: May 2017 / Accepted: November 2017)

\begin{abstract}
Since 2004, graphene has risen in popularity owing to its superior properties. However, limits to the scale of production methods have rendered graphene a costly material. Moreover, existing production methods require chemicals that are detrimental to the environment. This study uses Coconut Coir Dust (CCD) as a carbon precursor and an intermediate product in the manufacturing of graphene. Firstly, CCD sieved into a 100 mesh was carbonized using a hydrothermal method at temperatures of $235^{\circ} \mathrm{C}, 250^{\circ} \mathrm{C}$, and $265^{\circ} \mathrm{C}$, for 4 hours. Following this, the resulting solid residue was pyrolyzed at $1000^{\circ} \mathrm{C}$ for 2 hours under the protection of nitrogen (N2). The hydrothermal solid residue was labelled CHT (hydrothermal temperature) and the pyrolysis product was named as SP (hydrothermal temperature). Both samples were characterized using SEM, XRD and EDS. In addition, Raman characterization was conducted for SP samples. At the end of the process (SP), the XRD pattern showed two broad peaks centered around $2 \theta \sim 24^{\circ}$ and $44^{\circ}$ corresponding to a (002) and (100) graphite plane. This pattern is similar to that of reduced-graphene oxide. SEM images showed a sheet-like microstructure is caused by undegraded lignin. A perforated and corrugated sheet formed after pyrolysis, which subsequently confirms the formation of reduced-graphene oxide. Furthermore, the Raman result indicates that higher hydrothermal temperatures lead to an increasing integrated ID/IG ratio. The ratios were 1.62, 1.71 and 1.77, for SP 235, SP 250, and SP 265, respectively. Research results conclude that the carbonaceous material formed through hydrothermal and pyrolytic processes contained a mixture of an amorphous-carbon form and a graphene-like cluster. Results additionally show a similar structure with reduced-graphene oxide.
\end{abstract}

Keywords: Carbonization; Graphene; Hydrothermal; Pyrolysis; Reduced Graphene Oxide

\section{INTRODUCTION}

Graphene is considered to be sp2-hybridized carbon that is one atom thick. Its extended hexagonal network can be stacked into graphite, rolled to form nanotubes, and wrapped into fullerenes (Allen et al., 2010). In 2004, Geim and Novoselov isolated a single layer of graphene which was first thought to be thermodynamically unstable in room temperature. Since then, graphene has garnered increasing interest among scientists owing to its exceptional electrical

\footnotetext{
*Corresponding author's email: cipta255@gmail.com, Tel: +62-857-8996-8242, Fax: +62-274-489715

Permalink/DOI: https://doi.org/10.14716/ijtech.v8i8.731
} 
and mechanical properties (Geim \& Novoselov, 2007). As a result of these properties, graphene can be applied in various fields, especially in the storage of electrical energy. For example, graphene has been widely used as a cathode conductive agent, either as an additive (Honggowiranto \& Kartini, 2016) or as a composite (Sofyan et al., 2016). Challenges nevertheless arise as to how we establish a scalable method for graphene production.

Graphene synthesis methods are mainly classified into two approaches: bottom-up and topdown. The top-down approaches includes the exfoliation of graphite and the chemical reduction of graphite oxide. Graphene production using exfoliation methods generally gives a small amount of graphene, while the better-known Hummer method of chemical reduction offers more scalable but disordered graphene. However, the use of harmful chemical reactants in the Hummer method has a detrimental effect on the environment, particularly in large-scale production. The bottom-up method builds a hexagonal carbon structure from carbon precursors like biomass. Well known methods for this approach include Chemical Vapour Deposition (CVD) and Epitaxial Growth on silicon carbide. Through CVD, Ruan et.al. have produced high quality graphene from various different carbon sources, including cookies, insects, plastics and grass. However, CVD approaches tend to be unreliable when scaled up, since the process requires a thin metallic substrate. Moreover, epitaxial growth requires an expensive silicon carbide (Muramatsu et al., 2014). The production of graphene-like material from coconut coir dust has been done, but it requires high temperatures of up to $1500^{\circ} \mathrm{C}$ (Barin et al., 2013). The research described in this study aims to provide a scalable method for the production of carbon material containing graphene domains, by varying hydrothermal temperatures followed by pyrolysis.

\section{METHODS}

The coconut coir used in this study was obtained from Serpong Market as waste from coconut milk production. The coconut coir dust was separated from its coir before being sieved into a 100 size mesh. The coir dust is denoted as CCD from here-on-in. Hydrothermal preparation was conducted by adding 1 gram of CCD into a Teflon-lined stainless steel autoclave, then distilled water was added to around $70 \%$ of the autoclave volume for over 4 hours and at different temperatures of $235^{\circ} \mathrm{C} ; 250^{\circ} \mathrm{C} ; 265^{\circ} \mathrm{C}$. The resulting hydrothermal residue, denoted from now as CHT, was filtered, washed with distilled water, and then dried in an oven at $165^{\circ} \mathrm{C}$. All CHT samples were pyrolyzed under a nitrogen atmosphere at $1000^{\circ} \mathrm{C}$ for over 2 hours. From this point, the resulting pyrolysis product is referred to as SP.

The microstructural morphology of all samples for each process was investigated using a Scanning Electron Microscope (SEM, Jeol JSM - 6510LA), and the constituents of samples were characterized using EDS. The crystal structure was measured using XRD (PANalytical, $\mathrm{Cu} \mathrm{K} \alpha=1.54096 \AA$ ). The carbon structure of pyrolysis product was determined by Raman Spectroscopy using a wavelength of $785 \mathrm{~nm}$. The Raman data processing routine was conducted by adopting the routine used in the research of Mcdonald-wharry et al. (2013) for background and photoluminescence substraction. The fitting method carried out adopted that of Sadezky (2005).

\section{RESEARCH METHODOLOGY}

\subsection{X-ray Diffraction Result}

The raw materials were analyzed by X-ray diffraction to reveal their structure. An XRD diffractogram of coconut coir dust is shown in Figure 1.

Owing to its high lignin content (Rahayu et al., 2014), the XRD pattern of CCD shows a rough background contributed by highly amorphous lignin (Luo et al., 2011). The coconut coir 
diffraction pattern exhibits a prominent peak at $2 \theta \sim 22^{\circ}$ assigned to a (200) cellulose crystal plane. Moreover, there was a broad and weak peak centered at $15^{\circ} 2 \theta$ reflection, explained by a (110) crystalline plane of cellulose overlapping with a $18^{\circ}$ amorphous cellulose peak (Poletto et al., 2014).

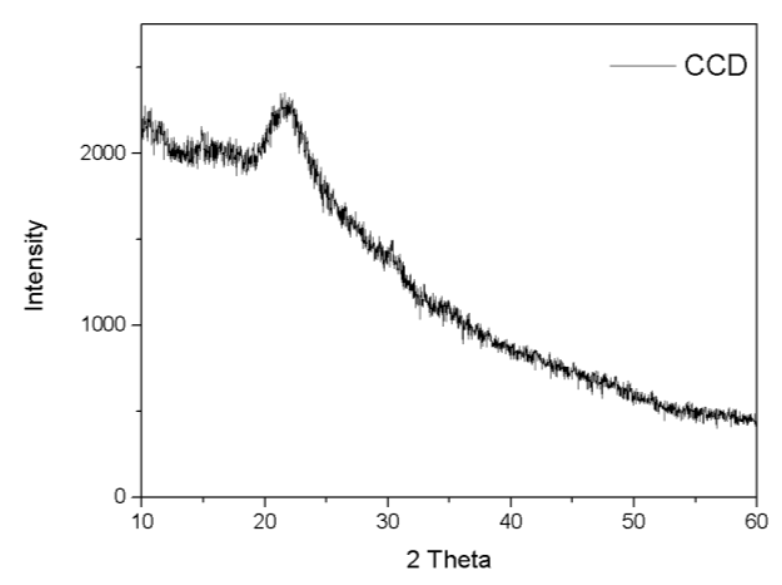

Figure 1 XRD pattern of Coconut Coir Dust (CCD)

The carbonization process was necessary to cleave carbon-hydrogen and carbon-oxygen bonding. Hydrothermal methods are one of the most suitable for carbonizing lignocellulosic materials because it is less energy intensive compared to pyrolysis for 'wet' biomass (Funke \& Zieglier, 2010). Hydrothermal carbonization incorporates a complex reaction in which simultaneous reactions occur at once, but the process is initialized by the hydrolysis of lignin, hemicellulose, and cellulose embodied in CCD. Products of degradation may further undergo decarboxylation, dehydration, condensation, and even aromatization (Reza et al., 2014). Since carbon bonded in cellulose and hemicelluse is in linear chains, the aromatization may occur during the process (Sevilla \& Fuertes, 2009).
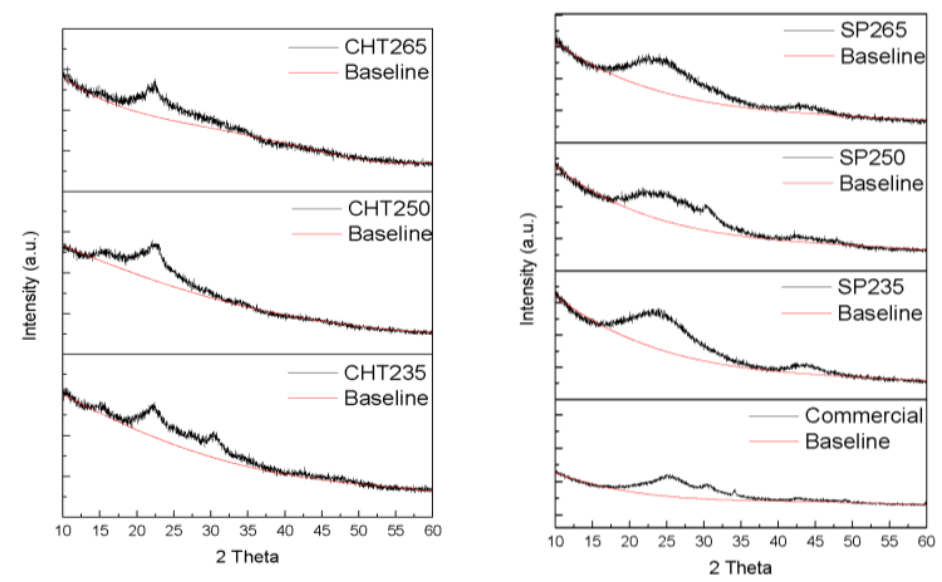

Figure 2 CHT XRD pattern for temperature variation (left), SP XRD pattern (right)

In the research presented here, a hydrothermal method was carried out at varied temperatures ranging from $235^{\circ} \mathrm{C}$ to $265^{\circ} \mathrm{C}$, as shown in Figure 2. The crystalline (200) cellulose peak remained in all of the CHT diffraction patterns but the amorphous phase descreased for CHT 235 and CHT 265. Normally, cellulose degrades at $200^{\circ} \mathrm{C}$ under hydrothermal conditions (Funke \& Zieglier, 2010). However, cellulose started to degrade at $240^{\circ} \mathrm{C}$ and crystalline cellulose was hardly degraded at all when lignin was present in the biomass (Falco et al., 
2011). Lignin only partially reacted during the hydrothermal process owing to its complex structure (Funke \& Zieglier, 2010).

Interestingly, even at lower temperatures, the amorphous phases of cellulose were already degraded. The bulging peak centered at $2 \theta \sim 18^{\circ}$ observed for CHT 250 relates to aliphatic chains formed during the degradation of biomass (Manoj \& Kunjomana, 2012). Besides this, the occurrence of a peak around $2 \theta=30^{\circ}$ was associated with impurities, although it is still unclear which elements this indicates. No carbon-related peaks can be ascertained. Further study is necessary to identify peak attributes.

Pyrolysis was carried out at $1000^{\circ} \mathrm{C}$ under a nitrogen $\left(\mathrm{N}_{2}\right)$ atmospheric condition to avoid carbon oxidation. The XRD result showed completely different patterns owing to pyrolysis. This result consisted of distinct, broad peaks ranging from $2 \theta \sim 17^{\circ}$ to $32^{\circ}$, and a weak peak centered at $\sim 43^{\circ}$. These peaks are assigned as (002) and (001) graphite planes, respectively. However, despite the (002) graphite plane, the first broad peaks centered at $\sim 25^{\circ}$, showing a lower reflection than pristine graphite at around $27^{\circ}$, thus exhibiting a higher level of interlayer d-spacing. Furthermore, the broadened peak behaviour indicates the yielding of carbonaceous materials stacked turbostratically into the (002) plane of graphite (Manoj \& Kunjomana, 2012). The emergence of these peaks further indicates the formation of reduced-graphene oxide (rGO)-like materials (Blanton et al., 2013).

\subsection{Scanning Electron Microscopy Images}

Figure 3 represents the SEM image of: (a) CCD; (b) CHT 235; (c) CHT 250; and (d) CHT 265. Unsurprisingly, after the hydrothermal process, only slight differences can be observed throughout the images.

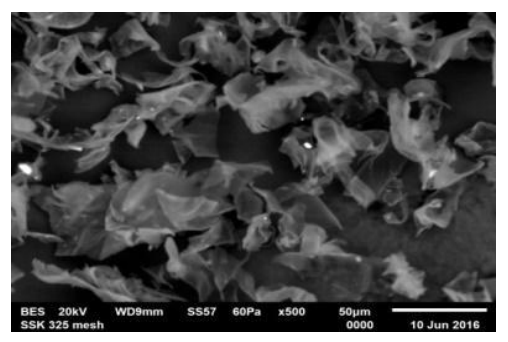

(a)

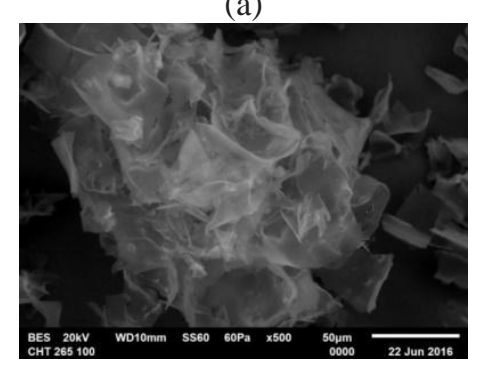

(d)

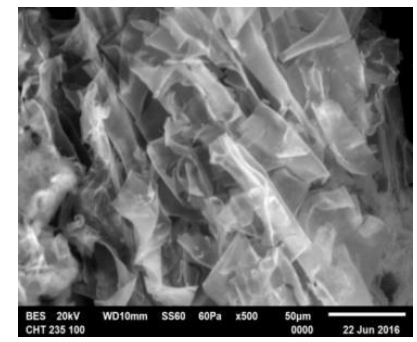

(b)

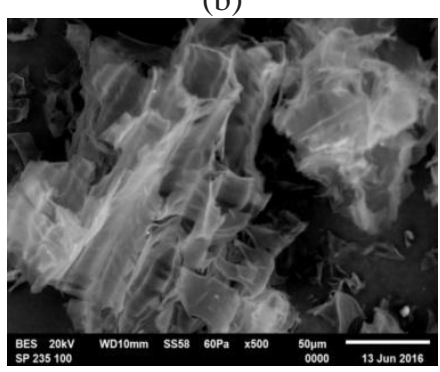

(e)

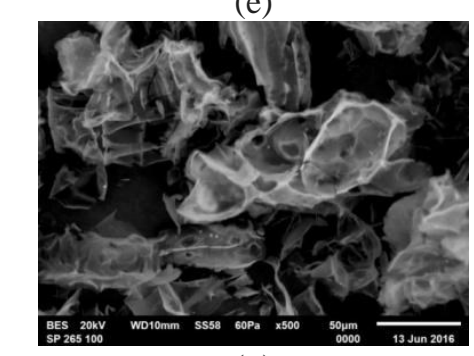

(g)

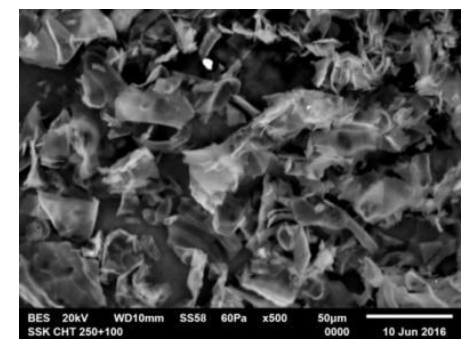

(c)

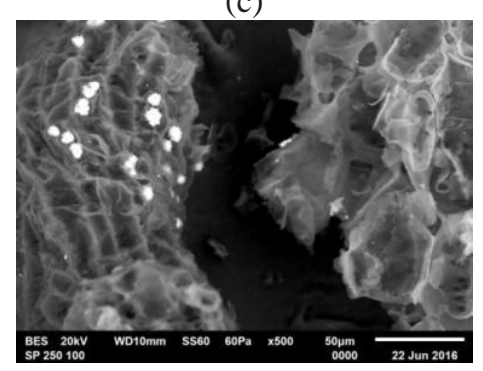

(f)

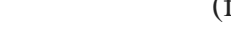


All hydrothermal products exhibit a similar morphology - a sheet-like structure - to CCD, owing to high lignin composition; lignin generally exhibits a more complex structure. Moreover, lignin acts as a hard bio-template while keeping cellulose contained inside (Barin et al., 2013).

The microstructural images of pyrolytically treated samples, SP, are shown in Figures (3e) SP 235; (3f) SP 250; (g) SP 265. Although they all exhibited a similar sheet-like structure, corrugated and perforated sheets could also be observed. During the hydrothermal process, lignin was partially degraded and this resulted in a perforated structure (Dinjus et al., 2011). The corrugated sheet images of SP were related to the attributes of wrinkled graphene (Fu et al., 2013). SEM characterization subsequently confirms the formation of rGO-like carbon.

Both the hydrothermal and pyrolytic methods aimed to increase the carbon composition of CCD. The changes in carbon content are shown in Table 1.

Table 1 EDS result summary of CCD, CHT and SP samples

\begin{tabular}{ccccccc}
\hline \multirow{2}{*}{ Sample } & \multirow{2}{*}{$\begin{array}{c}\text { Hydrothermal } \\
\text { Temp. }\left({ }^{\circ} \mathrm{C}\right)\end{array}$} & \multicolumn{7}{c}{$\%$ atom } \\
\cline { 3 - 7 } & - & 65.66 & 33.67 & 0.23 & 0.20 & 0.23 \\
\hline CCD & 235 & 73.65 & 26.35 & - & - & - \\
\multirow{3}{*}{$\mathrm{CHT}$} & 250 & 76.68 & 23.32 & - & - & - \\
& 265 & 76.07 & 23.93 & - & - & - \\
\hline \multirow{3}{*}{$\mathrm{SP}$} & 235 & 92.95 & 7.05 & - & - & - \\
& 250 & 93.05 & 6.95 & - & - & - \\
& 265 & 92.79 & 7.21 & - & - & - \\
\hline
\end{tabular}

Raw materials, CCD, contained $65.66 \%$ carbon atoms and $33.67 \%$ oxygen, and contributed both from the atoms bonded in lignin and cellulose. The hydrothermal process carbonized the sample slightly, increasing its carbon contents to higher than $70 \%$ - specifically, $73.65 \%$; 76.68\%; 76.07\% for CHT 235, CHT 250, CHT 265, respectively. Pyrolytic treatment also increased the carbon content to $92.95 \%$; 93.05\%; $92.79 \%$ for SP 235; SP 250; SP 265, respectively. From the CHT sample, there was only $\sim 4$ to $5 \%$ difference in carbon content that could be observed between CHT 235 and CHT 250, which indicates that higher temperatures cause more severe reactions, including decarboxylation and dehydration. In summary, data determined that hydrothermal processes not only carbonize the sample but also remove inorganic extractives, including $\mathrm{Na}, \mathrm{Cl}$, and $\mathrm{K}$.

\subsection{Raman Result, D Band and G Band}

Generally, carbonaceous materials exhibit two prominent peaks in the Raman spectra. These are denoted as $\mathrm{D}$ band and $\mathrm{G}$ band. The $\mathrm{G}$ band emerges from $\mathrm{E}_{2 \mathrm{~g}}$ symmetry of sp2-hybridized carbon, either in chains or in aromatic bonding. Graphite shows a $\mathrm{G}$ band of $\sim 1580 \mathrm{~cm}^{-1}$. The occurrence of the $\mathrm{D}$ band relate to disordered $\mathrm{sp}_{2}$ carbon. However, only $\mathrm{sp}_{2} \mathrm{C}$ bonded in aromatics and with a close proximity to an edge or disordered carbon can produce this band. Concurrently, the D band producing carbon spectra could not be identified as truly amorphous, and is instead regarded as nanocrystalline graphite (Mcdonald-wharry et al., 2013). The D3 band at $\sim 1500 \mathrm{~cm}^{-1}$ is attributed to the amorphous carbon phase (Jawhari et al., 1995), while the presence of D4 correlates with $\mathrm{sp}_{3}$ bonded carbon and is also assigned as nanocrystalline diamond (Schwan et al., 1996).

The Raman spectra of SP 235, SP 250, and SP 265 is presented in Figure 4. The SP samples 
show a broadening $\mathrm{D}$ band, now denoted as D1, and $\mathrm{G}$ band. The commercial graphene shows a similarly broadened peak too. In order to discern the carbons, peaks must be deconvoluted. The first order of Raman spectra is deconvoluted into 5 peaks, as has been reported in the work of Sadezky et. al, each denoted as D1, D2, D3, D4, and G, and initially positioned at $\sim 1350 \mathrm{~cm}^{-1}, \sim 1600 \mathrm{~cm}^{-1}, \sim 1500 \mathrm{~cm}^{-1}, 1100 \mathrm{~cm}^{-1}$, and $1580 \mathrm{~cm}^{-1}$, respectively. Although the D3 band is thought to fit correctly into a Gaussian function, in this report, the given method results in the overlapping of the D3 and D1 band, which further hampers our comprehension of the peaks. peaks fitted into the Lorentzian shape. The results of this fitting are summarized in Table 2 and Table 3.
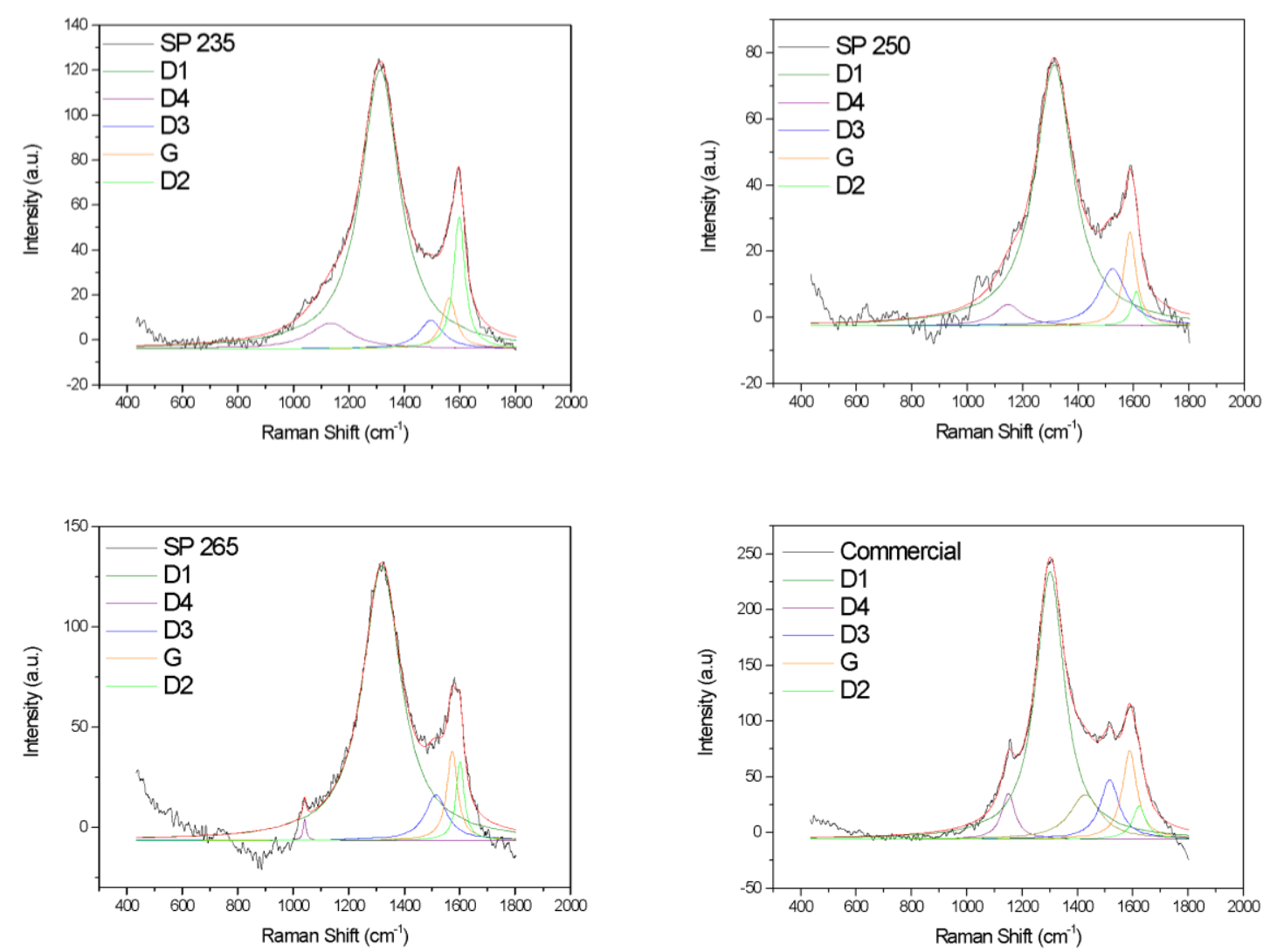

Figure 4 Lorentzian peak fitting result for each SP and Commercial graphene sample

The G, D1, and D2 band are attributed to the in-plane graphitic lattice and normally occur in graphite Raman spectra. According to the table, the width of G, D1, and D2 band show a decreasing trend in correlation with increases in hydrothermal temperature. Moreover, the narrower band indicates that the carbon bond tends to be more organized. This conclusion arises owing to the graphite exhibiting a small FWHM of those three peaks, with HighlyOrdered Pyrolytic Graphite (HOPG) showing even narrower peaks (Sadezky, 2005). However, the D3 and D4 peaks show unclear correlation across all samples. The intensities of the G band were 22.6; 28.4; 44.4 for SP 235, SP 250, and SP 265, respectively.

Since the $G$ band correlates with sp2-hybridized carbon, the intensified peaks indicate an ordering or clustering of carbon atoms. In addition, the intensified and narrower $\mathrm{G}$ band can be further considered as an ordering of amorphous carbon (Muramatsu et al., 2014). As such, if the D3 band is determined as amorphous carbon, then logically, the intensity of D3 should be weakened as well. In fact, the Raman spectra shows an increasing intensity of the D3 band. Other assumptions are required to confirm G and D3 band trends. Kaniyoor and Ramaprabhu 
have shown that peaks around $1500 \mathrm{~cm}^{-1}$ denoted as $\mathrm{D}^{* *}$ also emerge in ball-milled graphite, indicating the formation of nanocrystalline graphite. Thus $\mathrm{D} * *$ or D3 attributed finite crystalline graphene rather than $\mathrm{sp}_{3}$ rich carbon materials (Kaniyoor \& Ramaprabhu, 2012). By adopting this assumption, it can be interpreted that the increase of $G$ band intensity is due to the formation of $\mathrm{sp}_{2}$ carbon, while the intensified D3 peaks show that the $\mathrm{sp}_{2}$ formed is similar to nano-crystalline graphite. This result shows that, at a higher hydrothermal temperature, more lignocellulose degrades and undergoes subsequent carbon aromatization in order to form small graphitic layers or graphene-like domains.

Table 2 Properties of fitted D4, D1, D3 peaks of raman spectra

\begin{tabular}{lrrrrrrrrr}
\hline \multirow{2}{*}{ Sample } & \multicolumn{3}{c}{ D4 } & \multicolumn{3}{c}{ D1 } & \multicolumn{3}{c}{ D3 } \\
\cline { 2 - 10 } & Position & FWHM & Intensity & Position & FWHM & Intensity & Position & FWHM & Intensity \\
\hline SP 235 & 1133.40 & 179.18 & 11.40 & 1312.86 & 168.26 & 124.00 & 1495.5 & 101.68 & 12.59 \\
SP 250 & 1147.23 & 117.59 & 6.42 & 1313.44 & 166.74 & 78.94 & 1524.5 & 117.36 & 17.24 \\
SP 265 & 1040.85 & 12.70 & 10.30 & 1319.41 & 167.04 & 136.73 & 1514.7 & 94.25 & 22.60 \\
commercial & 1150.13 & 58.99 & 41.08 & 1301.14 & 124.78 & 239.76 & 1516.4 & 82.98 & 53.10 \\
\hline
\end{tabular}

Table 3 Properties of fitted G and D2 peak band properties

\begin{tabular}{lrrrrrr}
\hline \multirow{2}{*}{ Sample } & \multicolumn{3}{c}{ G } & \multicolumn{3}{c}{ D2 } \\
\cline { 2 - 7 } & . Position & \multicolumn{1}{c}{ FWHM } & Intensity & Position & FWHM & Intensity \\
\hline SP 235 & 1561.53 & 60.31 & 22.58 & 1597.86 & 48.16 & 58.47 \\
SP 250 & 1586.74 & 52.71 & 28.38 & 1609.97 & 39.62 & 10.34 \\
SP 265 & 1573.07 & 46.34 & 44.36 & 1601.46 & 34.89 & 39.09 \\
commercial & 1588.75 & 63.03 & 79.50 & 1623.35 & 57.71 & 29.61 \\
\hline
\end{tabular}

Hydrothermal carbonization reactions are categorized into two pathways producing two different carbon structures. The first path is solid-solid conversion forming a carbon with a similar structure to its parent. In the second path, carbon produced from polymerization of the dissolved intermediates resulted in smaller carbon particles (Dinjus et al., 2011). In order to confirm the interpretation of Raman bands, the integrated $D$ band and $G$ band ratio should be calculated, as it inversely correlates with average crystallite size, La, as Tuinstra and Koenig have reported. Figure 4 below shows the integrated intensity ratio $\left(\mathrm{I}_{\mathrm{D}} / \mathrm{I}_{\mathrm{G}}\right)$.

Table 4 Result of integrated D and G band ratio (ID/IG) and averages crystallite size (La)

\begin{tabular}{ccc}
\hline Samples & $\mathrm{I}_{\mathrm{D}} / \mathrm{I}_{\mathrm{G}}$ & $\mathrm{L}_{\mathrm{a}}(\mathrm{nm})$ \\
\hline SP 235 & 1.62 & 2.70 \\
SP 250 & 1.71 & 2.54 \\
SP 265 & 1.77 & 2.45 \\
Commercial & 2.16 & 2.01 \\
\hline
\end{tabular}

As is shown in Table 4, the average crystallite size of SP 235, SP 250 and SP 265 are 2.70; $2.54 ; 2.45$, respectively. Moreover, commercial graphene shows a smaller average crystallitev size of 2,01 nanometers. This result illustrates consensus with the given interpretation of Raman bands, i.e. that nanocrystalline graphene-like domains formed at higher hydrothermal temperature can be shown in decreasing La. 

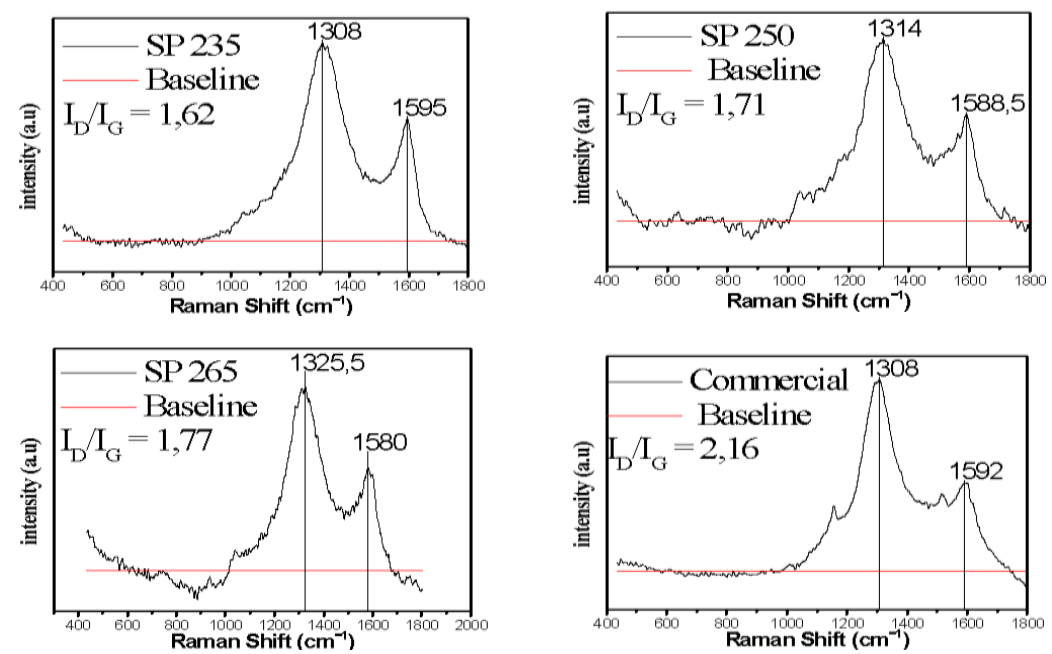

Figure 5 Position of integrated (maxima) intensities of D and G band for SP 235, SP 250, SP 265 and commercial graphene

\section{CONCLUSION}

Coconut coir dust exhibits a complex carbonization reaction when undergoing hydrothermal and pyrolytic treatment. The final carbon content for SP 235, SP 250, and SP 265 was 93\% atom. The crystal structure of carbon was furthermore determined by XRD, which illustrated the formation of a reduced-graphene oxide-like structure. The SEM images used in this paper confirm findings by showing the corrugated morphology of SP samples. For the purposes of comparison, commercial graphene was also tested using Raman, which showed a more nanocrystalline, graphene-like domain. Final investigations using Raman spectroscopy showed that SP 265 exhibited the smallest average crystallite size, with a more graphene-like domain being formed. However, this material requires further purification to separate graphene-like carbon and other amorphous carbon forms that are contained in the SP sample.

\section{ACKNOWLEDGEMENT}

This research was funded by the Ministry Research Technology and Higher Education through the Konsorsium Sistem Inovasi Nasional Research Grant, with the contract no. 278/SP2H/LT/DRPM/III/2016. The facilities used in this study were supported by the Centre for Science and Technology for Advanced Materials and the National Nuclear Energy Agency, Indonesia.

\section{REFERENCES}

Allen, M.J., Tung, V.C., Kaner, R.B., 2010. Honeycomb Carbon: A Review of Graphene. Chemical Reviews, Volume 110(1), pp. 132-145

Balachandran, M., Ag, K., 2012. Study of Stacking Structure of Amorphous Carbon by X-Ray Diffraction Technique. International Journal of Electrochemical Science, Volume 7, pp. 3127-3134

Barin, G.B., Santos, Y.H., Rocha, J.A., Barreto, L.S., 2013. Graphene-like Nanostructure Obtained from Biomass. Materials Research Society Symposia Proceedings, Volume 1505

Blanton, T.N., Majumdar, D., Company, E.K., 2013. Characterization of X-Ray Irradiated Graphene Oxide Coatings using X-Ray Diffraction, X-Ray Photoelectron Spectroscopy, and Atomic Force Microscopy. JCPDS - International Centre for Diffraction Data, pp. 
$116-122$

Dinjus, E., Kruse, A., Troger, N., 2011. Hydrothermal Carbonization - 1. Influence of Lignin in Lignocelluloses. Chemical Engineering \& Technology, Volume 12, pp. 2037-2043

Falco, C., Baccile, N., Titirici, M.-M., 2011. Morphological and Structural Differences between Glucose, Cellulose and Lignocellulosic Biomass Derived Hydrothermal Carbons. Green Chemistry, 13(11), pp. 3273-3281

Fu, C., Zhao, G., Zhang, H., Li, S., 2013. Evaluation and Characterization of Reduced Graphene Oxide Nanosheets as Anode Materials for Lithium-ion Batteries. International Journal of Electrochemical Science, Volume 8, pp. 6269-6280

Funke, A., Zieglier, F., 2010. Hydrothermal Carbonization of Biomass: A Summary and Discussion of Chemical Mechanism for Process Engineering. Biofuels, Bioproducts, and Biorefining, Volume 4(2), pp. 160-177

Geim, A.K., Novoselov, K.S., 2007. The Rise of Graphene. Nature Materials, Volume 6, pp. 183-191

Honggowiranto, W., Kartini, E., 2016. Characterization of $\mathrm{LiFePO}_{4}$ Cathode by Addition of Graphene for Lithium Ion Batteries. In: AIP Conference Proceedings, Volume 1710(1), pp. $1-8$

Jawhari, T., Roid, A., Casado, J., 1995. Raman Spectroscopic Characterization of Some Commercially Available Carbon Black Materials. Carbon, Volume 33(11), pp. 1561-1565

Kaniyoor, A., Ramaprabhu, S., 2012. A Raman Spectroscopic Investigation of Graphite Oxide Derived Graphene a Raman Spectroscopic Investigation of Graphite Oxide Derived Graphene. In: AIP Advances, Volume 2(3), pp. 1-13

Luo, J., Genco, J., Cole, B., Fort, R., 2011. Lignin Recovered from the Near-neutral Hemicellulose Extraction Process as a Precursor for Carbon Fiber. Bioresources, Volume 6(4) pp. 4566-4593

Mcdonald-wharry, J., Manley-harris, M., Pickering, K., 2013. Carbonisation of BiomassDerived Chars and the Thermal Reduction of a Graphene Oxide Sample Studied using Raman Spectroscopy. Carbon, Volume 59, pp.383-405

Muramatsu, H., Kim, Y.A., Yang, K-S., Cruz-Silva, R., Toda, I., Yamada, T., Terrones, M., Endo, M., Hayashi, T., Saitoh, H., 2014. Rice Husk-Derived Graphene with Nano-Sized Domains and Clean Edges. Small, Volume 10(14), pp. 2766-2770

Poletto, M., Junior, H.L.O., Zattera, A.J., 2014. Native Cellulose: Structure, Characterization and Thermal Properties. Materials, Volume 7(9), pp. 6105-6119

Rahayu, L.H., Purnavita, S., Sriyana, H.Y., 2014. Coconut Coir and Coconut Potency as Adsorbent for Oil Regeneration (Potensi Sabut dan Tempurung Kelapa sebagai Adsorben untuk Meregenerasi Minyak Jelantah). Momentum, Volume 10(1), pp. 47-53 (in Bahasa)

Reza, M.T., Uddin, M.H., Lynam, J.G., Hoekman, S.K., Coronella, C.J., 2014. Hydrothermal Carbonization of Loblolly Pine: Reaction Chemistry and Water Balance. Biomass Conversion and Biorefinery, Volume 4(4), pp. 311-321

Sadezky, A., Muckenhuber, H., Grothem H., Niessner, R., Poschl, U., 2005. Raman Microspectroscopy of Soot and Related Carbonaceous Materials : Spectral Analysis and Structural Information. Carbon, Volume 43(8), pp. 1731-1742

Schwan, J., Ulrich, S., Batori, V., Ehrhardt, H., Silva, S.R.P., 1996. Raman Spectroscopy on Amorphous Carbon Films. Journal of Applied Physics, Volume 80(1), pp. 440-447

Sevilla, M., Fuertes, A.B., 2009. The Production of Carbon Materials by Hydrothermal Carbonization of Cellulose. Carbon, Volume 47(9), pp. 2281-2289

Sofyan, N., Putro, D.Y., Zulfia, A., 2016. Performance of Vanadium-Doped $\mathrm{LiFePO}_{4} / \mathrm{C}$ used as a Cathode for a Lithium Ion Battery. International Journal of Technology, Volume 7(8), pp. $1307-1315$ 